\title{
The Rating of Operating Performance of Domestic Auto Industry
}

\author{
Kuo-Wei Lin, Chia-Mu Kuan and Ming-Huang Ni \\ Department of International Business, Hsuan Chuang University, Hsinchu, 30092, R.O.C., Taiwan
}

Received 2012-07-11, Revised 2012-09-10; Accepted 2012-09-11

\begin{abstract}
The financial crisis in 2007 delivered a setback to the auto industry in Taiwan. However, the domestic auto companies had adopted various contingency measures that not only overcame the economic downturns but also enhanced their operating performances. It was the perfect storm. This study focuses on the changes of operating performances by domestic auto companies in Taiwan after financial crisis and explores their operating strategies. TOPSIS Model is designed to set the criteria for choosing optimal solutions under the condition that multiple objectives need to be met. Due to the obvious characteristics shown in TOPSIS Model, corporations tend to favor its use in developing a model for operating performance appraisal. This study extracted the financial information disclosed by the listed companies and conducted appraisal. After practical verification, we found that operating performance was indeed related to the ranking orders of the analysis in rating model. In applying the rating model developed in the study, executives will be able to view a better big picture before forming solid strategies. Besides, it may provide stock investors an alternative reference in selecting stocks.
\end{abstract}

Keywords: Operating Performance, Competition Strategy, TOPSIS Model, Multi-Objective Evaluation, Management Decision-Making, Entropy Weight

\section{INTRODUCTION}

Auto industry is one of industries that the Taiwan government has exerted great efforts to protect. In order to foster the growth of domestic auto industry in Taiwan, for a long time, the government has levied high tarrif on imported cars. However, after entry into World Trade Organization (WTO) in 2002, Taiwan could not use high tariff policy to protect domestic auto industry any more. On the contrary, it had to reduce the import tax from 60 to $30 \%$ and furthered to reduce to $17.5 \%$ in 2011 . The measures devastated the industry that lacked of brand innovation and independent research and development.

After abolitishing the trade protection policies, naturally, the imported cars' competitive edge has increased. But according to statistics (2011) of the Taiwan Transportation Vehicle Manufactures Association (TTVMA) (Table 1), even though the number of imported cars sales have significant growth, the local manufactured cars have not been knocked out. Instead, the local manufactured car manufactures exerted greater efforts on $R \& D$ and innovation by launching the car models that are more suitable for the demands of local consumers. They also commit themselves to the enhancement of customer satisfaction with services that the sales volume grew from 345,211 in 2002 to 444,470 in 2005.

But the break-out of financial crisis reduced the number of sales of local manufactured cars to 306,388 (reduced 31.26\%) in 2006, 271,665 (reduced 11.33\%) in 2007 and furthered to reduce to 186,753 (reduced $31.26 \%$ ) in 2008. However, in 2009, Taiwan government timely announced the subsidy policy to waive excise taxation by NT $\$ 30,000$ for buying each new car to encourage consumers to buy local manufactured cars. In the meantime, in coupling with government's incentive policy, each local motor company also developed their own operation strategies to reinvigorate consumer confidence. In 2009, the number of sales of local manufactured cars increased to 233,979 , grew $25.29 \%$ comparing to the previous year, thus the auto industry walked out of the financial crisis.

Corresponding Author: Kuo-Wei Lin, Department of International Business, Hsuan Chuang University, Hsinchu, 30092, R.O.C., Taiwan 
Table 1. The Sales of Cars in Taiwan during 2002-2011

\begin{tabular}{|c|c|c|c|c|c|c|c|c|}
\hline \multirow[b]{2}{*}{ Year } & \multicolumn{3}{|c|}{ Local Manufactured Cars } & \multicolumn{3}{|c|}{ Imported Cars } & \multicolumn{2}{|l|}{ Total } \\
\hline & $\begin{array}{l}\text { Number of } \\
\text { Sales }\end{array}$ & $\begin{array}{l}\text { Growth } \\
\text { Rate (\%) }\end{array}$ & $\begin{array}{l}\text { Market } \\
\text { Share (\%) }\end{array}$ & $\begin{array}{l}\text { Number } \\
\text { of Sales }\end{array}$ & $\begin{array}{l}\text { Growth } \\
\text { Rate (\%) }\end{array}$ & $\begin{array}{l}\text { Market } \\
\text { Share (\%) }\end{array}$ & $\begin{array}{l}\text { Number } \\
\text { of Sales }\end{array}$ & $\begin{array}{l}\text { Growth } \\
\text { Rate }(\%)\end{array}$ \\
\hline 2002 & 345211 & 18.50 & 86.54 & 53671 & -4.35 & 13.46 & 39882 & 14.81 \\
\hline 2003 & 357285 & 3.50 & 86.32 & 56629 & 5.51 & 13.68 & 413914 & 3.77 \\
\hline 2004 & 422410 & 18.23 & 87.22 & 61882 & 9.28 & 12.78 & 484292 & 17.00 \\
\hline 2005 & 444470 & 5.22 & 86.37 & 70157 & 13.37 & 13.63 & 514627 & 6.26 \\
\hline 2006 & 306388 & -31.07 & 83.64 & 59928 & -14.58 & 16.36 & 366316 & -28.82 \\
\hline 2007 & 271665 & -11.33 & 83.13 & 55116 & -8.03 & 16.87 & 326781 & -10.79 \\
\hline 2008 & 186753 & -31.26 & 81.37 & 42744 & -22.45 & 18.63 & 229497 & -29.77 \\
\hline 2009 & 233979 & 25.29 & 79.47 & 60444 & 41.41 & 20.53 & 294423 & 28.29 \\
\hline 2010 & 252722 & 8.04 & 77.14 & 74893 & 23.77 & 22.86 & 327615 & 11.27 \\
\hline 2011 & 281198 & 11.27 & 74.33 & 97090 & 29.64 & 25.67 & 378288 & 15.47 \\
\hline
\end{tabular}

In summarizing operation strategies of auto manufacturers, we could divide them into two parts: (1) improvement strategy in markets: strengthening staff training, requiring on-site employees to observe the demands from customers and designing the car models that the customers really need. They implemented a clear outline of responsibilities and bonus system to help enhance production and sales. Employees who performed well were undoubtedly promoted. (2) The improvement strategies on production line: advocating the combination of hi-tech and humanity, emphasizing especially on safety and comfort of the configuration by equipping airbags and various overhauling improvements in the bodywork where they used titanium casting sheet and environment-friendly waterborne coatings. They also took advantage of electronic and computer technology to manufacture diversified models, such as modern, luxury, exquisite fuel-efficient and hybrid models to offer more choices to customers.

After withstanding the trauma of financial crisis, each domestic motor company was able to get back on its feet and continue to evolve. Therefore, the purpose of the study is to establish a model to rate the operating performance of each domestic motor company and find out which operating strategy is the most effective.

\section{TOPSIS MODEL}

This study used the TOPSIS Model, a technique introduced by Yoon and Hwang (1995) in which similar ideal solution is preferably selected in rating the operating performance. The TOPSIS Model is to assist decision-makers, facing multiple criteria that need to reach maximum satisfaction, find out the solution closest to the ideal answer under the circumstance that they do not know the trade offs. Hwang and Yoon directly transcribed the performance values of each option into the coordinate values of multiple dimensions before finding out ideal performance value of each measurement indicator under the ideal condition to construct the coordinates of the ideal solution. By using the worst condition of each measurement indicator, they used the minimum performance value of each measurement indicator to construct the coordinate of the worst solution. Then they calculated the distance between each option as well as ideal solution coordinates and the worst solution coordinates. Using such method to determine the quality of rated solution is applying the idea of Euclidean Space distance. When the distance between a rated solution and the most ideal solution coordinates is smaller and to the worst solution coordinates is greater, the rated solution is better. On the contrary, if the distance of the rated solution to the most ideal solution is greater and to the worst solution is smaller, the rated solution is worse.

But the solution closest to the ideal solution is not necessarily the farthest to the worst solution; similarly, the solution farthest to the worst solution is not necessarily the closest to the most ideal solution. Often the two conditions do not occur simultaneously. For example, in Fig. 1, Solutions $\mathrm{A}_{1}$ and $\mathrm{A}^{+}$(Ideal Solution) is the closest, but Solution $\mathrm{A}_{2}$ is the farthest to Solution $\mathrm{A}^{-}$(Worst Solution). In this position, it is rather difficult to judge which solution is better. For that we shall go into the trading-off principles.

The trading-off principles of TOPSIS are based on the indifference curve idea in economics to determine the quality of solutions. So the overall performance index is defined as:

$\mathrm{p}=\frac{\mathrm{D}^{-}}{\mathrm{D}^{-}+\mathrm{D}^{+}}$ 


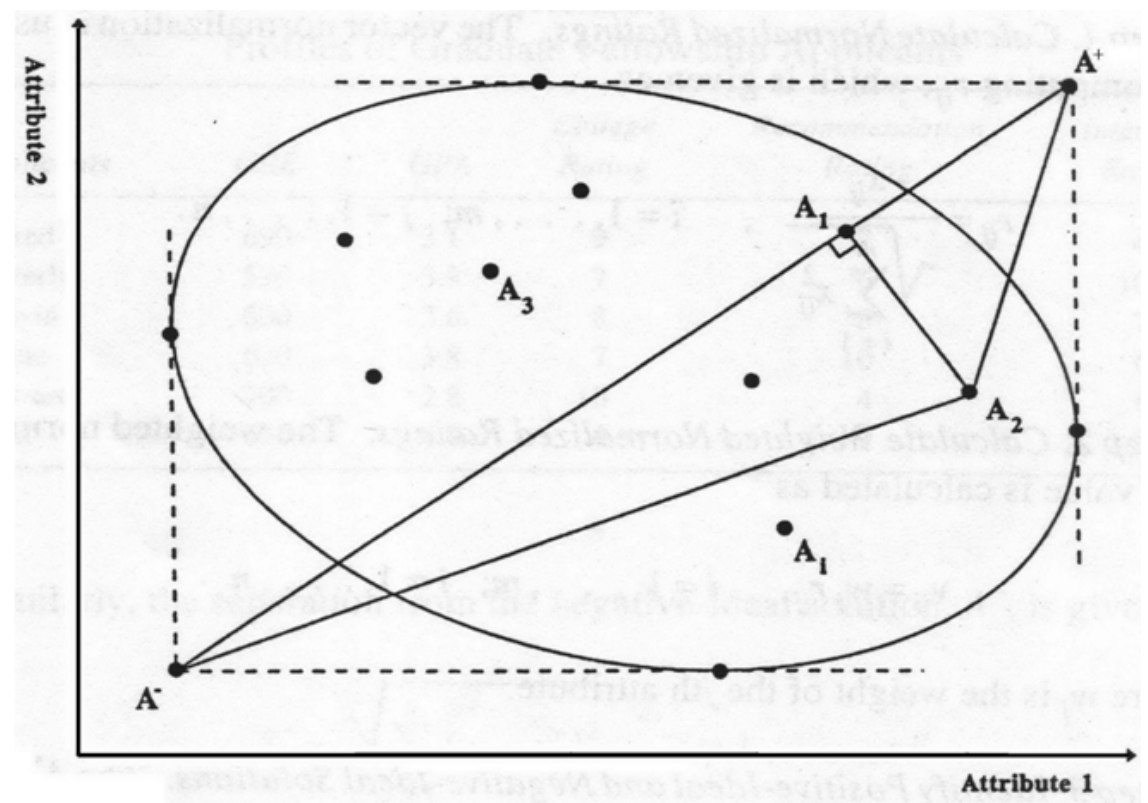

Fig. 1. The Distance of Optional Solutions to the Ideal Solution and the Worst Solution Source: Yoon and Hwang (1995)

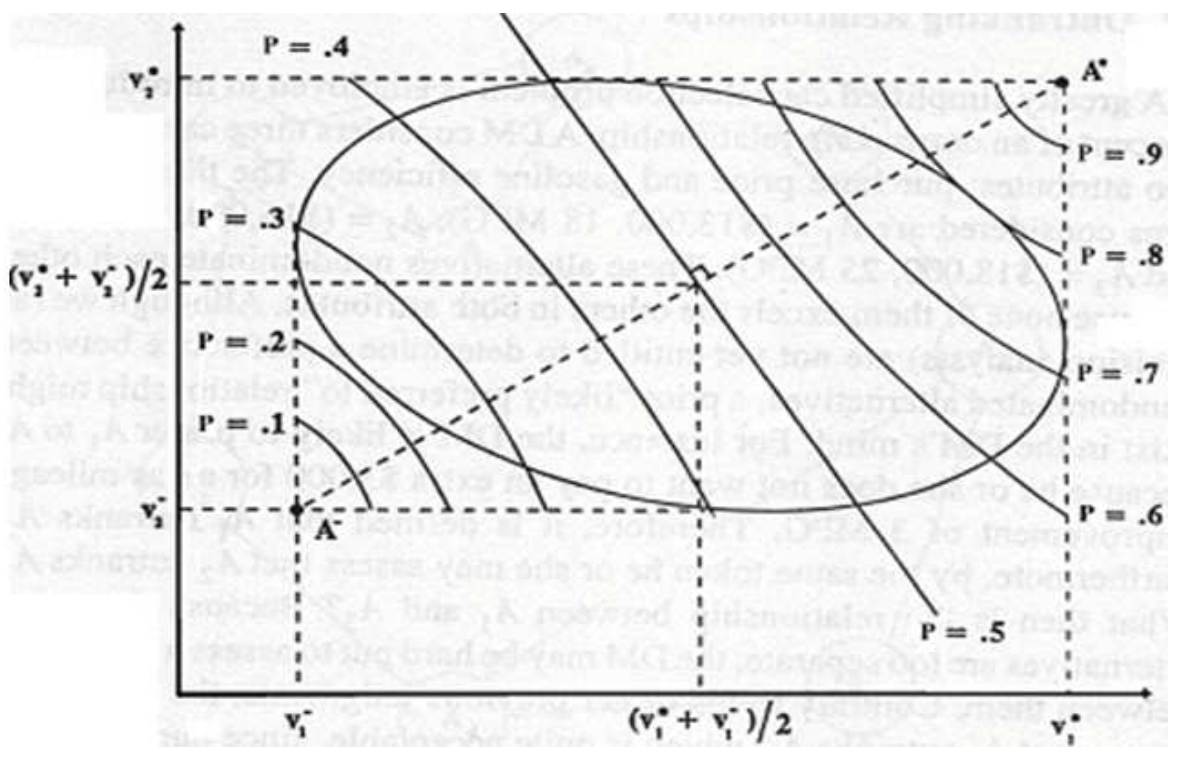

Fig. 2. The Relationship between Indifference Curves and Optional Solutions Source: Yoon and Hwang (1995)

In which, $\mathrm{D}^{-}$is the distance to the least desired value whereas $\mathrm{D}^{+}$is the distance to the most desired value, $p$ value is the overall performance index and its range is between 0 and 1 . After transposition and simplification, we obtain:

$\mathrm{pD}^{+}=(1-\mathrm{p}) \mathrm{D}^{-}$
The equation satisfies the set constituted by the condition: the measured distance ratio of $\mathrm{A}^{+}$to $\mathrm{A}^{-}$is (1p):p. Fig. 2 draws indifference curves of different $p$ values separately.

When $p=0.5$, any reference point on the indifference curve from $\mathrm{A}^{+}$to $\mathrm{A}^{-}$is the same, at this point in time, the distance between indifference and $\mathrm{A}^{+}$to $\mathrm{A}^{-}$is equal. 
When $\mathrm{p}>0.5$, the indifference curve is concaved to $\mathrm{A}^{+}$, here the indifference curve is closer to $\mathrm{A}^{+}$; the greater $\mathrm{p}$ value is, the more concave to $\mathrm{A}^{+}$the indifference curve will be. On the contrary, when $\mathrm{p}<0.5$, the indifference curve is more concaved to $\mathrm{A}^{-}$, the indifference curve is closer to $\mathrm{A}^{-}$and such proximity can be considered as risk prone, the smaller the $\mathrm{p}$ value is, the bigger the risk will be. Therefore, using indifference curve to select an ideal solution is a very good rating method.

\section{STEPS OF COMPUTATION}

Based on above-mentioned principles, here we set up the step-by-step computation as follows:

\subsection{Construct Decision Matrix}

After quantitative processing of each solution, the performance value of each measurement indicator is obtained and the following decision matrix is constructed as Table 2.

In this study, $A_{i}$ is the ith compared corporation for comparison and $\mathrm{C}_{\mathrm{j}}$ is the $\mathrm{jth}$ rated measurement indicator, so $\mathrm{x}_{\mathrm{ij}}$ is the $\mathrm{jth}$ rated indcator value of the ith corporation.

\subsection{Transfomed into Normalized Decision Matrix}

Due to the quantity order of each rating indicator not being the same, it would be unfair to hastily rate them on the same level that should be normalized in the first place. In making reference to Triantaphyllou and Lin (1996) method, the study processed the element of each rating indicator by transcribing the vector into unit vector, i.e.:

$$
r_{i j}=\frac{x_{i j}}{\sqrt{\sum_{i=1}^{m} x_{i j}{ }^{2}}}
$$

\subsection{Construct Weight Normalized Matrix}

Let $w$ be the weight is given to each rating indicator:

$\mathrm{w}=\left(\mathrm{w}_{1}, \mathrm{w}_{2}, \mathrm{w}_{3}, \ldots, \mathrm{w}_{\mathrm{n}}\right)$

Then the weight norm decision matrix is defined as:

$$
\mathrm{V}=\left(\mathrm{r}_{\mathrm{ij}} \mathrm{w}_{\mathrm{j}}\right)=\left(\mathrm{v}_{\mathrm{ij}}\right)
$$

Table 2. The Decision Matrix

\begin{tabular}{llllll}
\hline Alternative & $\mathrm{C}_{1}$ & $\mathrm{C}_{2}$ & $\mathrm{C}_{3}$ & $\ldots$ & $\mathrm{C}_{\mathrm{n}}$ \\
\hline$A_{1}$ & $x_{11}$ & $x_{12}$ & $x_{13}$ & $\ldots$ & $x_{1 n}$ \\
$A_{2}$ & $x_{21}$ & $x_{22}$ & $x_{23}$ & $\ldots$ & $x_{2 n}$ \\
$A_{3}$ & $x_{31}$ & $x_{32}$ & $x_{33}$ & $\ldots$ & $x_{3 n}$ \\
$:$ & $:$ & $:$ & $:$ & $:$ & $:$ \\
$A_{m}$ & $x_{m 1}$ & $x_{m 2}$ & $x_{m 3}$ & $\ldots$ & $x_{m n}$ \\
\hline
\end{tabular}

\subsection{Determine the Coordinates of the Ideal Solution and the Worst Solution}

The ideal coordinate is:

$$
\begin{aligned}
& \mathrm{A}^{+}=\left(\begin{array}{l}
\left(\max _{\mathrm{i}} \mathrm{v}_{\mathrm{ij}} \mid \mathrm{j} \in \mathrm{J}^{+}\right) \operatorname{or}\left(\min _{\mathrm{i}} \mathrm{v}_{\mathrm{ij}} \mid \mathrm{j} \in \mathrm{J}^{-}\right) \\
\mid \mathrm{i}=1,2,3, \ldots, \mathrm{m}
\end{array}\right) \\
& =\left(\mathrm{v}_{1}^{+}, \mathrm{v}_{2}^{+}, \mathrm{v}_{3}^{+}, \ldots, \mathrm{v}_{\mathrm{n}}^{+}\right)
\end{aligned}
$$

which is comprised of the best value of each rated indicator.

The coordinate of the worst solution is:

$$
\begin{aligned}
& A^{-}=\left(\begin{array}{c}
\left(\min _{i} v_{i j} \mid j \in J^{+}\right) \text {or }\left(\max _{i} v_{i j} \mid j \in J^{-}\right) \\
\mid i=1,2,3, \ldots, m
\end{array}\right) \\
& =\left(v_{1}^{-}, v_{2}^{-}, v_{3}^{-}, \ldots, v_{n}^{-}\right)
\end{aligned}
$$

which, is comprised of the worst value of each rated indicator.

Because:

$\mathrm{J}^{+}=\{\mathrm{j}=1.2,3, \ldots \mathrm{n} \mid \mathrm{j}$ associated with the benefit criteria $\}$

And:

$\mathrm{J}^{-}=\{\mathrm{j}=1.2,3, \ldots \mathrm{n} \mid \mathrm{j}$ associated with the cos t criteria $\}$

Therefore, in considering the principle by benefits, we will choose the maximum value of all measurement indicators as the coordinate value of ideal solution whereas in considering principle by cost, we will choose the minimum value of all measurement indicators as the coordinate value of ideal solution. Similarly, in considering principle by benefits, we will choose the minimum value of all measurement indicators as the coordinate value of the worst solution whereas in considering principles by cost, we will choose the maximum value of all measurement indicators as the coordinate value of the worst solution. 


\subsection{Compute Separate Measurement}

The separate measurement of the ideal solution coordinates and the worst solution coordinates to each optional solution can be computed separately by Euclidean space idea on distance. Then the separate measurement to the ideal solution coordinates is:

$$
\mathrm{D}_{\mathrm{i}}^{+}=\sqrt{\sum_{\mathrm{j}=1}^{\mathrm{n}}\left(\mathrm{v}_{\mathrm{ij}}-\mathrm{v}_{\mathrm{j}}^{+}\right)^{2}}
$$

whereas, the separate measurement to the worst solution coordinates is:

$$
D_{i}^{-}=\sqrt{\sum_{j=1}^{n}\left(v_{i j}-v_{j}^{-}\right)^{2}}
$$

\subsection{Compute Overall Performance Index}

The overall performance index is defined as:

$$
\mathrm{p}_{\mathrm{i}}=\frac{\mathrm{D}_{\mathrm{i}}^{-}}{\mathrm{D}_{\mathrm{j}}^{-}+\mathrm{D}_{\mathrm{j}}^{+}}
$$

\section{DETERMINE THE WEIGHT OF ASSESSED INDICATOR}

Due to the fact that each measurement indicator is not the same, we shall give weight $\mathrm{w}_{\mathrm{j}}$ to each indicator in order to satisfy the requirement that the sum of total weight values should be 1 , that is:

$$
\sum_{j=1}^{n} w_{j}=1
$$

In this study, we adopted entropy weight method to compute the weight of each rating indicator. In physics, the meaning of entropy is defined by the degree of molecular chaos of a system under a particular state. Feng (1988) extended the concept of entropy; he introduced event occurrence $\mathrm{E}$ and its measurement in the degree of surprise. The degree of surprise is determined by the probability of occurrence in an event. The higher the probability of the occurrence of $E$ is, the lower the degree of surprise caused by the occurrence of $\mathrm{E}$ will be. So we only need minimum information to explain the causes of the occurrence of event E. On the contrary, the lower the probability of the occurrence of $\mathrm{E}$ is, if event $\mathrm{E}$ does occur, the higher the degree of surprise will be. Still, we need to extract as much information as possible in order to explain the occurrence of $\mathrm{E}$.

Therefore, Feng and Chen (1992) took advantage of the probability of event occurrence to define the entropy value in a single event $\mathrm{E}$, then the entropy value is:

$$
h(p)=\ln \left(\frac{1}{p}\right)=-\ln p
$$

The equation represents the degree of surprise caused by the occurrence of E. In addition, it also defines sample space and expected entropy value in reference to the concept of mathetical expectation value. Once in the sample space, the probability of occurrence of Event $E_{1}$, $E_{2}, .$. and $E_{n}$ become $p_{1}, p_{2}, \ldots$ and $p_{n}$ respectively, then the expected entropy value of sample space is:

$\mathrm{H}=\sum_{\mathrm{i}=1}^{\mathrm{n}} \mathrm{p}_{\mathrm{i}} \ln \left(\frac{1}{\mathrm{p}_{\mathrm{i}}}\right)=-\sum_{\mathrm{i}=1}^{\mathrm{n}} \mathrm{p}_{\mathrm{i}} \ln \mathrm{p}_{\mathrm{i}}$

The equation represents the average degree of surprise of sample space or the uncertainty in miscommunication decision information. Therefore, in formula (3), if $r_{i j}$ is the $j$ th rating indicator value of the ith solution after normalization, then we can derive the $j$ th rating indicator, the probability of occurrence of the ith solution is:

$\mathrm{p}_{\mathrm{ij}}=\mathrm{r}_{\mathrm{ij}} / \sum_{\mathrm{i}=1}^{\mathrm{m}} \mathrm{r}_{\mathrm{ij}}$

According to formula (15), the expected entropy value of the jth rating indicator is:

$$
H(j)=-\sum_{i=1}^{m} p_{i j} \ln p_{i j}
$$

Because when $p_{1 j}=p_{2 j}=p_{3 j}=\ldots=p_{m j}=\frac{1}{m}, H(j)$ has its maximum value, i.e.,:

$\operatorname{Max} \cdot H(j)=-\sum_{i=1}^{m} \frac{1}{m} \ln \frac{1}{m}=\ln m$

In order to make sure the entropy value represents the uncertainty degree of decision information that transmits, it is necessary to require the value to be between 0 and 1 . So we define the entropy value of each rating indicator as: 


$$
e(j)=\frac{H(j)}{\ln m}
$$

Let the degree of certainty of decision information of the indicator that transmits be 1-e ( $\mathrm{j})$, so we can define the relative importance (i.e. objective weight) of the rating indicator:

$$
w(j)=(1-e(j)) /\left(\sum_{j=1}^{n}(1-e(j))=(1-e(j)) /\left(n-\sum_{j=1}^{n} e(j)\right)\right.
$$

\section{RESULTS}

In the report of corporation competitiveness, Jin (2004) argued that the rating should include four factors: scale, growth, profit and brand. However, it is difficult to establish an objective standard for the measurement value of the brand factor, the competitiveness model developed by the study will forsake it. In addition, in order to establish a comprehensive rating model, in this study, we will add two more factors: efficiency factor and risk factor.
The contents and formulas of the five selected factors and 13 rating indicators are shown as Table 3.

From the posted financial statements of five listed local car manufacturers in Taiwan shown on Table 3. Extract materials from and compute their rating indicators as Table 4. Some of the indicators in growth factor did not grow comparing to 2010; thus the negative growth value will affect the outcome of the entropy weight. As a result, the study changed all growth indicator values to be the quotients from 2011 data being divided by 2010 data (no more deduct 1) to make sure that all growth indicators are positive values.

Substitute the rating values in Table 4 into Formula (3) and obtain the data of each rating indicator after normalization. Again, substitute the data into formula (16) to (20) and obtain weight of each indicator (please refer to Table 5).

Multiply the normalized values by weight values and obtain Weight Normalized Decision Matrix as shown in Table 6.

\begin{tabular}{|c|c|c|}
\hline Category & Ratio & Formula \\
\hline \multirow{3}{*}{ Scale Factor } & Revenue Scale & 2011 Revenue /Total 2011 revenue of all corporations \\
\hline & Profit Scale & 2011 Profit /Total 2011 profit of all corporations \\
\hline & Equity Scale & 2011 Equity /Total 2011 equity of all corporations \\
\hline \multirow{3}{*}{ Growth Factor } & Revenue Growth Rate & (2011 Revenue $/ 2010$ Revenue) ${ }^{1 / 3}-1$ \\
\hline & Profit Growth Rate & (2011 Profit /2007 Profit $)^{1 / 3}-1$ \\
\hline & Equity Growth Rate & (2011 Equity /2007 Equity) $^{1 / 3}-1$ \\
\hline \multirow{3}{*}{ Profit Factor } & Return on Assets & 2011 Net Profit/2011 Average Assets \\
\hline & Return on Equity & 2011 Net Profit/2011 Average Equity \\
\hline & Net Profit Rate & 2011 Net Profit /2011 Revenue \\
\hline \multirow{2}{*}{ Efficiency Factor } & Asset Turnover Rate & 2011 Revenue /2011 Average Assets \\
\hline & Accounts Receivable Turnover Rate & 2011Revenue /2011 Average Account Receivables \\
\hline \multirow{2}{*}{ Risk Factor } & Current Ratio & 2011 Current Assets/2011 Current Liabilities \\
\hline & Quick Ratio & 2011 Quick Assets /2011 Current Liabilities \\
\hline
\end{tabular}

Table 3. The definitions of rating indicators of five factors

\begin{tabular}{|c|c|c|c|c|c|c|c|c|c|c|c|c|c|}
\hline \multirow[b]{2}{*}{ Company } & \multicolumn{3}{|c|}{ Scale Factor (\%) } & \multicolumn{3}{|c|}{ Growth Factor (\%) } & \multicolumn{3}{|c|}{ Profit Factor (\%) } & \multicolumn{2}{|c|}{ Efficiency Factor } & \multicolumn{2}{|c|}{ Risk Factor } \\
\hline & Revenue & Profit & $\begin{array}{l}\text { Net } \\
\text { Assets }\end{array}$ & Revenue & Profit & $\begin{array}{l}\text { Net } \\
\text { Assets }\end{array}$ & ROA & ROE & $\begin{array}{l}\text { Net } \\
\text { Profit }\end{array}$ & $\begin{array}{l}\text { Asset } \\
\text { Turnover }\end{array}$ & $\begin{array}{l}\text { Account } \\
\text { Receivable } \\
\text { Turnover }\end{array}$ & $\begin{array}{l}\text { Current } \\
\text { Ratio }\end{array}$ & $\begin{array}{l}\text { Quick } \\
\text { Ratio } \\
\end{array}$ \\
\hline Yulon & 17.90 & 19.49 & 38.09 & 1.21 & 0.87 & 1.04 & 4.78 & 5.62 & 9.20 & 0.52 & 25.78 & 234.05 & 154.44 \\
\hline China Motor & 16.62 & 16.68 & 25.59 & 1.13 & 1.06 & 1.04 & 6.08 & 7.16 & 8.48 & 0.70 & 17.80 & 268.91 & 192.53 \\
\hline Sanyang & 10.85 & 6.78 & 8.66 & 1.22 & 1.79 & 1.10 & 5.10 & 8.86 & 5.28 & 0.84 & 21.52 & 143.48 & 43.87 \\
\hline Hotai & 39.78 & 36.07 & 16.11 & 1.16 & 1.36 & 1.15 & 20.25 & 25.80 & 7.66 & 2.48 & 84.77 & 197.43 & 157.06 \\
\hline Yulon Nissan & 14.86 & 20.98 & 11.55 & 1.17 & 1.33 & 1.14 & 16.88 & 20.86 & 11.93 & 1.30 & 70.54 & 151.53 & 148.95 \\
\hline
\end{tabular}

Table 4. The rating data of five local car corporations 
Table 5. Rating indicator and weight values after normalization

\begin{tabular}{|c|c|c|c|c|c|c|c|c|c|c|c|c|c|}
\hline \multirow[b]{2}{*}{ Company } & \multicolumn{3}{|c|}{ Scale Factor (\%) } & \multicolumn{3}{|c|}{ Growth Factor (\%) } & \multicolumn{3}{|c|}{ Profit Factor (\%) } & \multicolumn{2}{|c|}{ Efficiency Factor } & \multicolumn{2}{|c|}{ Risk Factor } \\
\hline & Revenue & Profit & $\begin{array}{l}\text { Net } \\
\text { Assets }\end{array}$ & Revenue & $\begin{array}{l}\text { Net } \\
\text { Profit }\end{array}$ & Assets & ROA & ROE & $\begin{array}{l}\text { Profit } \\
\text { Rate }\end{array}$ & $\begin{array}{l}\text { Net } \\
\text { Asset } \\
\text { Turnover }\end{array}$ & $\begin{array}{l}\text { Account } \\
\text { Receivables }\end{array}$ & $\begin{array}{l}\text { Current } \\
\text { sRatio }\end{array}$ & $\begin{array}{l}\text { Quick } \\
\text { Ratio }\end{array}$ \\
\hline Yulon & 0.3568 & 0.3942 & 0.7508 & 0.4598 & 0.2959 & 0.4234 & 0.1711 & 0.1582 & 0.4686 & 0.1705 & 0.2210 & 0.5112 & 0.4663 \\
\hline China Motor & 0.3312 & 0.3373 & 0.5044 & 0.4281 & 0.3582 & 0.4250 & 0.2176 & 0.2015 & 0.4319 & 0.2295 & 0.1526 & 0.5873 & 0.5813 \\
\hline Sanyang & 0.2163 & 0.1371 & 0.1707 & 0.4628 & 0.6070 & 0.4506 & 0.1825 & 0.2494 & 0.2689 & 0.2754 & 0.1845 & 0.3134 & 0.1325 \\
\hline Hotai & 0.7928 & 0.7294 & 0.3176 & 0.4396 & 0.4606 & 0.4691 & 0.7247 & 0.7262 & 0.3902 & 0.8129 & 0.7267 & 0.4312 & 0.4742 \\
\hline YulonNissan & 0.2962 & 0.4243 & 0.2277 & 0.4448 & 0.4511 & 0.4657 & 0.6041 & 0.5872 & 0.6077 & 0.4261 & 0.6047 & 0.3310 & 0.4497 \\
\hline Weight & 0.0894 & 0.0909 & 0.1097 & 0.0003 & 0.0233 & 0.0008 & 0.1493 & 0.1374 & 0.0260 & 0.1296 & 0.1561 & 0.0230 & 0.0640 \\
\hline
\end{tabular}

Table 6. The best values, worst values and weight normalized matrix

\begin{tabular}{|c|c|c|c|c|c|c|c|c|c|c|c|c|c|}
\hline \multirow[b]{3}{*}{ Company } & \multicolumn{3}{|c|}{ Scale Factor (\%) } & \multicolumn{3}{|c|}{ Growth Factor } & \multicolumn{3}{|c|}{ Profit Factor (\%) } & \multicolumn{2}{|c|}{ Efficiency Factor } & \multicolumn{2}{|c|}{ Risk Factor } \\
\hline & & & Net & & & Net & & & Net Profit & $t$ Asset & $\begin{array}{l}\text { Account } \\
\text { Receivable }\end{array}$ & nt & Quick \\
\hline & Revenue & Profit & Assets & Revenue & Profit & Assets & ROA & ROE & Rate & Turnover & Turnover & Ratio & Ratio \\
\hline Yulon & 0.031912 & 0.035824 & 0.082354 & 0.000152 & 0.006896 & 0.000320 & 0.025547 & 0.021743 & 0.012204 & 0.022098 & 0.034496 & 0.011756 & 0.029863 \\
\hline China Motor & 0.029624 & 0.030647 & 0.055331 & 0.000142 & 0.008349 & 0.000322 & 0.032495 & 0.027701 & 0.011249 & 0.029747 & 0.023818 & 0.013507 & 0.037228 \\
\hline Sanyang & 0.019346 & 0.012460 & 0.018722 & 0.000153 & 0.014146 & 0.000341 & 0.027257 & 0.034278 & 0.007004 & 0.035696 & 0.028796 & 0.007207 & 0.008483 \\
\hline Hotai & 0.070917 & 0.066281 & 0.034831 & 0.000146 & 0.010734 & 0.000355 & 0.108228 & 0.099816 & 0.010161 & 0.105389 & 0.113431 & 0.009917 & 0.030369 \\
\hline Yulon Nissan & 0.026491 & 0.038561 & 0.024976 & 0.000147 & 0.010512 & 0.000352 & 0.090217 & 0.080704 & 0.015825 & 0.055244 & 0.094390 & 0.007611 & 0.028801 \\
\hline Best Value & 0.070917 & 0.066281 & 0.082354 & 0.000153 & 0.014146 & 0.000355 & 0.108228 & 0.099816 & 0.015825 & 0.105389 & 0.113431 & 0.013507 & 0.037228 \\
\hline WorstValue & 0.019346 & 0.012460 & 0.018722 & 0.000142 & 0.006896 & 0.000320 & 0.025547 & 0.021743 & 0.007004 & 0.022098 & 0.023818 & 0.007207 & 0.008483 \\
\hline
\end{tabular}

Table 7. The over performance and rating sequence

\begin{tabular}{lllll}
\hline Company & Distance to the Best Value & Distance to the Worst Value & Performance Value & Sequence \\
\hline Yulon & 0.1693 & 0.0733 & 0.3021 & 3 \\
China Motor & 0.1687 & 0.0530 & 0.2390 & 4 \\
Sanyang & 0.1828 & 0.0206 & 0.1011 & 5 \\
Hotai & 0.0486 & 0.1850 & 0.7920 & 1 \\
Yulon Nissan & 0.0986 & 0.1225 & 0.5541 & 2 \\
\hline
\end{tabular}

Again substitute the values in Table 6 into Formula (10) and (11) and obtain the separate measurement in each corporation including the ideal solution and the worst solution coordinates (Table 7). Then substitute two sets of values into Formula (12) to figure out Overall Performance Index of each corporation and establish sequence of operating performance of each corporation.

\section{DISCUSSION}

In Table 7, we could learn that the highest ranking is Hotai among overall performance values of car manufactures, followed by Yulon Nissan, Yulon, China Motor, Sanyang Hynudai.

The top-ranked Hotai Motor provides various vehicle manufactured by Kuozui Motor which mainly manufactures Toyota cars, so Hotai is also an agent of Toyota and Lexus. Its market share in Taiwan is 35\%. With a total of eight distributors, 128 outlets. It offers five models of automobile under 2,000 cc.: Vios, Yaris, Altis, Wish and Camry 2.0. They sell more models of cars than any other manufacturers, their sales of cars under 2,000 cc accounts for $1 / 4$ of total car sales. Hotai is a major choice for car-purchasing consumers. In addition, the models under 2,000 cc accounts for more than $70 \%$ of their total sales. Other than 2008, affected by financial crisis when sales reduced, stats steadily grew. In 2009, sales bounced back to the level of 2007 and grew again for $2.5 \%$ in 2010 . In Table 4, its revenue scale is $39.78 \%$, profit scale $36.0 \%$, ROA $20.25 \%$, ROE $25.80 \%$ and account receivable turnover 84.77. All of which ranked the first place in its respective category. In Table 7, Hotai has the closest distance to the best value 0.0486 , it also has the farthest distance to the worst value 0.1850 . Therefore Hotai has the most excellent operating performance.

Yulon Nissan, ranking second, is a joint-venture of Yulon and Nissan. The company mainly sells Nissan and Infiniti models. For Nissan, the models include MARCH, VERITA, TIIDA, BLUEBIRD, SERENA, TEANA series, X-TRAIL, QUEST AND MURANO series. For INIFITI, the models include Q45 M M3 VG35 Sedan 、 G35 Coupe - FX45 and FX35 series. In Table 4, it shows Yulon-Nissan having higher rankings in profit- 
related indicators, such as profit scale 20.98\%, ROA $16.88 \%$, ROE 20.86\% and Profit Margin 11.93. There are two major obstacles that stood in Yulon-Nissan's way: the appreciation of Japanese Yen and the changes of steel prices in the international markets. Yulon Nissan should timely reflect on the exchange rates and steel prices of its market prices so that it can better keep up with the growth rates of revenue, profit and net assets for more than $14 \%$ (please refer to Table 4).

The third ranking Yulon aggressively took initiative and sought after its own research and development in technology after establishing joint-venture car sales company with with Nissan. The company not only manufactures Nissan-branded cars, it also manufactures and develops its own multi-branded cars. In addition, Yulon implemented OEM production for foreign auto companies, mainly to completely deal with the vehicle production for Nissan and Luxgen. Presently, it continues the OEM production and sales of NISSAN, INFINITI, CADILLAC, BUICK, OPEL, RENAULT AND and UD brand cars and develops its own brands, LUXGEN MPV/SUV/CEO and economic models such as M car. Yulon's financial system is formidable and healthy, owing no long-term debts. Though, its overall performance value ranked the third.

China Motor, which ranked fourth, signed technology cooperation agreement with Mitsubishi Motors since its establishment. It focuses on the production of commercial pick-up trucks and expands to oversee markets. It mainly sells Veryca, Colt Plus, Lancer Fortis and Outlander models. However, limited by the impact of the downturn of intonation economic situation, China Motor ranked lower in the growth factor (Table 4), for example, the revenue grew only $1.13 \%$ and profit and net assets grew $1.06 \%$ and $1.04 \%$ respectively. What's worse is that China Motor has higher liability ratio, accounting for about $40 \%$ of total assets; its cost of capital is rather expensive. The burden held back the growth of revenue. It is only natural that their operating performance is inferior to other companies mentioned above.

Sanyang Industry, which ranked the last, is only the corporation in Taiwan that manufactures both cars and motorbikes. In the earlier years before technology made its advances and introduced the likes of Civic into the markets, Sanyang produced models of Fugui and Facai with Japanese Honda and obtained a high market share in Taiwan. Later on, they suspended the cooperation with Honda and commenced to work with Hyundai. Sanyang introduced Elantra Touring Car and diesel SUV Tuscon. But due to higher operating cost, accounting for $90 \%$ of total revenue, after ducting all costs from gross profit, the net profit is extremely limited. Samyang is even under a high ratio of liability, in Table 4, its revenue scale is $10.85 \%$ and profit scale $6.78 \%$ and net asset scale $8.66 \%$, a heavy burden of long-term debts accounting for about $50 \%$ of total assets. From Table 7, we could also find their farthest distance to the best value 0.1828 and the closest distance to the worst value 0.0206 . With such bleak numbers, it is natural that their operating performance ranked the last.

\section{CONCLUSION}

This study is to construct a fair and objective operating performance rating model without too much preexisting limits to deliberately fit the known status of the corporations. Subjects taken out of its natural tendencies to merely fit an analysis would completely disturb the balance that the data intend to show. The better the operating performance rating is, the more capable the corporation is to present better operating strategy, creating desirable operating performance in the face of ever changing external environment.

Although the study did not directly explore the share price of each company, the investors should be careful in buying the stock of the corporation that was rated as inferior operating performance. As Hagstrom (2002) mentioned, anyone who is knowingly taking reckless risks could ultimately result in the predicament of a gambler's ruin. Be vigilant.

\section{REFERENCES}

Feng, C.M., 1988. Explanation and application of entropy in transportation. Commun. Transport., 10: 57-65.

Feng, C.M. and C.F. Chen, 1992. The determination of criteria weights-compromised weighting method. Commun. Transport., 14: 51-67.

Hagstrom, R.G., 2002. The Essential Buffett: Timeless Principles for the New Economy. 1st Edn., Wiley, New York, ISBN-10: 0471151033, pp: 304.

Jin, P., 2004. The Report on China's Enterprises Competitiveness. 1st Edn., Social Sciences Academic Press, China.

Triantaphyllou, E. and C.T. Lin, 1996. Development and evaluation of five fuzzy multiattribute decisionmaking methods. Int. J. Approximate Reason., 14: 281-310. DOI: 10.1016/0888-613X(95)00119-2

Yoon, K. and C.L. Hwang, 1995. Multiple Attribute Decision Making: An Introduction. 1st Edn., Sage Publications, ISBN-10: 0803954867, pp: 75. 
Kuo-Wei Lin et al. / Journal of Computer Science 8 (11) (2012) 1822-1829 